Research Article

\title{
Investigating Mobile Banking Continuance Intention: A Mixed-Methods Approach
}

\author{
Imdadullah Hidayat-ur-Rehman (D), Arshad Ahmad (iD, ${ }^{2}$ Muhammad Nauman Khan (iD, ${ }^{3}$ \\ and Shamsul Anuar Mokhtar $\mathbb{i D}^{4}$ \\ ${ }^{1}$ Department of MIS, CBA, King Saud University, Riyadh, Saudi Arabia \\ ${ }^{2}$ Department of Management, CBA, King Saud University, Riyadh, Saudi Arabia \\ ${ }^{3}$ Finance Department, College of Business Administration, King Saud University, Riyadh, Saudi Arabia \\ ${ }^{4}$ UniKL MIIT, University of Kuala Lumpur, Kuala Lumpur, Malaysia
}

Correspondence should be addressed to Imdadullah Hidayat-ur-Rehman; ihidayaturrehman@ksu.edu.sa

Received 15 March 2021; Revised 8 July 2021; Accepted 25 August 2021; Published 10 September 2021

Academic Editor: Floriano Scioscia

Copyright ( 92021 Imdadullah Hidayat-ur-Rehman et al. This is an open access article distributed under the Creative Commons Attribution License, which permits unrestricted use, distribution, and reproduction in any medium, provided the original work is properly cited.

\begin{abstract}
Building on IS research, this study investigates m-banking continuance from an emerging market perspective. Using a mixedmethods approach, the study presents m-banking continuance phenomenon through an integrated model. Study 1 focuses on qualitative interviews of mobile banking users, whereas study 2 empirically tests the conceptual model derived from literature and the results of study 1 . Study 1 reveals three additional constructs, perceived ubiquity, perceived autonomy, and perceived security concerns to the existing literature-based constructs. However, the results of study 2-a survey of 390 m-banking users-provide empirical evidence to support the hypotheses drawn in the proposed conceptual model. The results reveal that perceived ubiquity, perceived usefulness, satisfaction, facilitating conditions, perceived security concerns, and trust have emerged as significant direct influencers on m-banking continuance. Moreover, the study offers practical academic and managerial implications regarding m-banking.
\end{abstract}

\section{Introduction}

No doubt, with the incremental convenience and usability characteristic, mobile banking (m-banking) stands imperative in recent times for both consumers and financial institutions $[1,2]$. M-banking not only is significant to consumers and financial institutions but also lets business entities gain competitive advantage [3,4]. Recent literature insights depict that an investment of around $\$ 115$ billion has been made globally by banks to facilitate their customers [5]. Such an investment justifies the importance of $\mathrm{m}$-banking in addition to convenience; it also gives the ease of use for its consumers while performing various banking operations. In addition to the aspect of usefulness amid wide-ranging banking operations for its consumers, it also helps financial institutions in reducing the cost of their traditional financial services.
The extant literature suggests that most researchers have shown their inclination toward knowing the acceptance or adoption of m-banking [6-8]. However, an understanding of the postadoption phase of $\mathrm{m}$-banking is generally overlooked or is being less explored $[4,9,10]$. Despite the limited or less explored findings presented in the existing $\mathrm{m}$-banking literature, it is also believed that there exists less evidence that highlights the critical determinants of continuous usage of m-banking services after its initial adoption $[8,11]$. Hence, to understand the consumer's postadoption behaviour from the perspective of $m$-banking, it is essential to identify and examine the key factors affecting the continuance intention of consumers.

In current times, businesses are keen on providing their e-services to consumers; however, the complicated nature of e-services' continuous provision makes it difficult to retain consumers [9]. To address such difficulties, the providers of 
e-services cannot just rely on the adoption of the service; rather, their focus on customer retention is of far more importance. M-banking, which mostly is inexpensive and easy, has relatively higher likelihood of customer switching behaviour [12, 13]. To counter or restrict consumer switching behaviour, organisations need to understand the significant factors influencing consumer decision-making in $\mathrm{m}$-banking. Therefore, for banks to improve their e-services and to make informed decisions, research should focus on the understanding of key factors that may lead to m-banking users' satisfaction and continuous usage intentions.

Due to the evolving nature of m-banking services, the research emphasis on portraying promising future insights has always stayed rigorous in the last few years [5, 14-19]. Various theoretical frameworks and methodological approaches have been used in past studies for extending m-banking research; however, sufficient information on the continuous usage of financial services after their initial adoption is still scarce [16]. Researchers have tested different models and theories to identify the influential factors of m-banking adoption [20] and mainly have relied on the acceptance of fundamental information systems (IS) and adoption theories such as the Theory of Planned Behaviour (TPB), Technology Acceptance Model (TAM), Diffusion of Innovation Theory (DIT), and Unified Theory of Acceptance and Use of Technology (UTAUT) [5, 10, 21-24]. Similarly, others have relied upon IS success theories, such as DeLone \&McLean IS Success Model [5] or the Task Technology Fit model [25].

To address the issues highlighted above, this study investigates m-banking continuance intentions from an emerging market perspective and contributes to $\mathrm{m}$-banking literature from theoretical, methodological, as well as contextual aspects. Firstly, this study focuses on postadoption behaviour along with pre-adoption, that is, m-banking continuance intention, which has been relatively overlooked in the m-banking context. Secondly, to exhibit the evaluative understanding of m-banking phenomenon, a mixedmethods approach is used. The mixed-methods approach not only provides a chance to thoroughly explore the $\mathrm{m}$-banking decision-making but has also allowed authors to investigate the underlying mechanism through which $\mathrm{m}$-banking continuance is formed. Thirdly, most of the m-banking studies have relied on survey methods with convenience sampling approaches $[2,3,18,26]$. This study followed a rigorous mixed-methods approach to develop a comprehensive framework explaining m-banking continuance. The process started by developing an initial conceptual model based on well-established theories and models such as UTAUT and the Expectation Confirmation Model (ECM). Following this, in-depth interviews were conducted to explore additional variables related to m-banking adoption and continuance. This process helped the authors develop a comprehensive framework that incorporates additional exogenous variables such as perceived ubiquity, perceived security concerns, and perceived autonomy to explain the m-banking usage continuance. Fourthly, from a contextual perspective, this study contributes to $\mathrm{m}$-banking literature by investigating m-banking continuance in an emerging economy, i.e., Saudi Arabia. To sum up, the study addresses the issues mentioned above and attempts to answer the following research questions: (1) what are the significant factors associated with m-banking adoption and continuance? (2) What is the underlying mechanism through which consumers' m-banking usage continuance is developed?

The remaining sections of the paper are organised as mentioned here: discussion about the theoretical underpinning of this research is given in the next section, followed by the conceptual model 1 . Study 1 , covering qualitative research, is then presented. Study 2 describes hypotheses and conceptual model development, quantitative analysis, and empirical validation of the proposed model. The last section provides a discussion on the results and conclusions.

\section{Mobile Banking in Saudi Arabia}

In Saudi Arabia, mobile systems are becoming popular in all walks of life. In Saudi Arabia, there were 40.20 million mobile connections, 32.23 million Internet users, and Internet penetration reached 93\% in January 2020 [27]. Both the public and private sectors in Saudi Arabia have invested about $\$ 2.14$ billion to build new smart systems [5]. The Saudi banks have welcomed mobile broadband penetration as the most advantageous technology. In Saudi Arabia, banks are providing state-of-the-art services to their customers [28]. The total volume of transactions in digital payments is projected to be $\$ 25,741$ million in 2021 [29]. According to a survey made by [30], 53\% of respondents are interested in online banking services. Conversely, $50 \%$ of Saudi banking consumers showed their intent to switch to other banks due to insufficient features of $m$-banking [5]. The findings of a comparative study made by [31] showed that m-banking users in UK are more satisfied than m-banking users in Saudi Arabia. This situation can raise questions on the effectiveness of $\mathrm{m}$-banking services to fulfil the expectations of Saudi banking consumers and to shrink the switching rate [5].

Continuity of e-service usage is a complicated issue because the users can easily switch to other service providers [32]. The providers of e-services cannot depend on adoption of a service only, and their focus should be on retention of the existing users [33]. Use of m-banking is voluntary and customers switching from one banking application to another is costless and easy; therefore, research should focus on finding such factors that influence continuance intention to use m-banking [13]. Despite large $\mathrm{m}$-commerce potential and technological developments, there is lack of sufficient information about the factors that influence the continued use of mobile financial service after adoption [16]. According to [12], researchers have investigated initial adoption instead of continuance intention and research on m-banking continuation intention is an important matter that needs researchers' attention. In the light of the above facts, it is important to investigate the postadoption behaviours to understand the factors that affect consumers' continuance intention to use m-banking. This study tries to fill the gaps of extant research on $\mathrm{m}$-banking adoption and continuance in the context of Saudi Arabia. 


\section{Theoretical Foundations}

Recent technological developments have significantly transformed financial services and their usage [3]. Online banking, especially m-banking, has also seen significant development and has emerged as an alternative to traditional offline and phone banking $[2,34,35]$. Past studies have investigated the initial adoption instead of continuance intention of $\mathrm{m}$-banking $[12,16]$. The literature has emphasised the need for further research to identify factors affecting users' continuance intentions for m-banking, especially in developing countries $[5,9,36]$.

Over time, various theoretical frameworks have been used to explore mobile service adoption and continuance $[5,9,11,20,21,37,38]$. However, this study intends to explore not only the pre-adoption but also the postadoption of m-banking users; we find the UTAUT [39] and ECM [40] to be appropriate frameworks to study $\mathrm{m}$-banking continuance. The following section discusses these models in relation to m-banking.

3.1. Expectation Confirmation Model. To study IS continuance, Ref. [40] proposed ECM by extending the expectation confirmation theory. ECM is composed of four variables: confirmation, perceived usefulness, satisfaction, and IS continuance intention. Confirmation and satisfaction cover the pre-acceptance stage, while positive confirmation of expectations leads to perceived usefulness. ECM posits that after initial use, the user forms an opinion and perception about the usefulness of the IS. Gradually, the users' perceptions about usefulness and confirmation of expectations enhance their satisfaction. Subsequently, the continuance intention is effected by perceived usefulness and satisfaction [40]. ECM helps understand users' behaviours in situations that cannot be understood through theories of initial adoption [12].

Prior research has used ECM to study users' IS continuance intention, and the results confirm that ECM has a significant predictive power to explain continuance intention in e-commerce contexts [41, 42]. ECM was incorporated by [12] with other theories (such as TAM and TTF) to examine the users' continued use of $\mathrm{m}$-banking. According to their results, the ECM constructs play a significant role in explaining the continuance intention to use m-banking. ECM was used by [11] to study the determinants of mobile banking continuance in Malaysia. Their results confirm the high exploratory power of ECM in the m-banking context. Similarly, Ref. [42] used ECM to investigate the determinants of continuance intention to use smartphone banking services and confirm the importance of ECM. The above facts indicate that the ECM model is appropriate to study the consumers' continuance intention.

3.2. Unified Theory of Acceptance and Use of Technology. UTAUT model was proposed by [39]. They integrated eight competing IS acceptance and adoption models. UTAUT suggests four elements: performance expectancy, effort expectancy, social influence, and facilitating conditions as significant determinants of usage intention and user behaviour. Furthermore, the theory incorporates age, gender, voluntariness, and experience as moderating variables on various relationships. Researchers have used UTAUT to explore the acceptance of wireless technologies by users [6]. Moreover, it has also been used to investigate the adoption of Internet/m-banking $[5,6,10,43,44]$. The findings confirm that the UTAUT model has a substantial predictive power to explain the intention to use Internet/m-banking [45].

Besides, to study the information systems' continued usage by consumers, researchers have integrated UTAUT and ECM/Expectation Confirmation Theory (ECT) [15, 46]. To explore insights about e-government, Ref. [46] integrated ECT with UTAUT to examine the users' continuation intention and posited that the integration of ECM with UTAUT could better explain the IS continuance. Ref. [42] used ECM to investigate the factors affecting continuation intention in m-banking, which confirmed that satisfaction and security concerns are essential determinants of continuation intention. To explore the postadoption behaviours toward mobile payments, Ref. [47] combined ECM with UTAUT and confirmed the direct significant effects of satisfaction, performance expectancy, effort expectancy, and trust on continuance intention. To examine the factors that influence the continuance intention to use mobile applications, Ref. [48] incorporated ECM with UTAUT2. Ref. [49] has also recommended incorporating UTAUT with other theories to obtain insightful information about consumers' decisions for m-banking.

Similarly, Ref. [45] has pointed out the need to incorporate other factors through which the phenomenon of $\mathrm{m}$-banking might be better explained. This shows that integrating ECM with UTAUT is an adequate choice to study the adoption and continuance of $\mathrm{m}$-banking. The following section elaborates on each of the constructs presented in these models and the relevant hypotheses.

3.3. ECM Constructs-Satisfaction, Perceived Usefulness, and Confirmation. According to [40], individuals' continuance intention for information systems depends upon their perceived usefulness and satisfaction from the system usage. Moreover, satisfaction is contingent on users' confirmation of expectations. Prior research has confirmed the vital role of satisfaction in predicting continuance intention $[38,50,51]$. The repurchase intention of the buyer is determined by the level of satisfaction [41]. The users may repeat their utilization in the future due to their higher satisfaction levels [52]. Therefore, satisfaction is the key element in establishing long-term relationships [42]. If the users are highly satisfied, they are more likely to continue the use of $\mathrm{m}$-banking. Thus, we posit the following:

H1. Satisfaction is positively related to continuance intention.

The ECM posits that perceived usefulness is an important determinant of satisfaction and continuance intention [40]. Perceived usefulness refers to an individual's belief as to what degree of using a system would 
improve their work performance [51]. Following the model proposed by [51], this study considers perceived usefulness and performance expectancy as synonymous with each other. Performance expectancy was defined by [39] as an individual's belief regarding the extent to which the use of the system will help in attaining improvements in job performance. The literature suggests that performance expectancy has significant impacts on users' acceptance of m-banking technology [2]. In the context of m-banking, users may find it useful in improving their performance by providing various benefits (economic benefits, convenience, etc.).

If perceptions of users about a system's usefulness in the pre-acceptance stage are disconfirmed, they may feel cognitive dissonance. In postadoption expectations, perceived usefulness is a crucial element to determine satisfaction, and behavioural intention is predicted by perceived usefulness [12]. It is evident from previous research that users' perceived usefulness positively affects their satisfaction and usage intention [12, 15, 46]. However, in m-banking, higher levels of users' perceptions about usefulness positively influence their satisfaction, resulting in their continuous use of m-banking. Hence, we suggest the following hypothesis:

H2. Perceived usefulness is positively related to (a) satisfaction and (b) continuance intention.

M-banking users attempt to adjust their perceptions of usefulness to reduce dissonance, and the confirmation of their expectations enhances perceived usefulness [50]. The users' perceptions about the usefulness of an IS are adjusted by confirming expectations when their initial perceptions about usefulness are not concrete [15]. ECM posits that satisfaction has two elements: pre-adoption expectations and postadoption expectations. Higher performance and/or lower expectations result in higher confirmation of expectations affecting consumer satisfaction [40]. The literature suggests that the users' confirmation of expectations enhances their satisfaction which is a crucial determinant of forming a long-term relationship between the customers and the banks $[25,53]$. If the use of m-banking fulfils users' expectations, their satisfaction level is enhanced accordingly [12]. Thus, we posit:

H3. Confirmation has positive impacts on (a) perceived usefulness and (b) satisfaction.

3.4. Effort Expectancy, Social Influence, and Facilitating Conditions. According to [39], effort expectancy is related to the ease of use. Different features of $\mathrm{m}$-banking, such as content design, user interfaces, and functional ability, provide more ease of use that influences its adoption [54]. Although satisfaction is not a part of the original UTAUT model, in specific environments, users' satisfaction can be more applicable than the behavioural intention [53]. Thus, satisfaction is applicable in the postadoption context.
In understanding postadoption behaviours, the literature has confirmed the crucial role of satisfaction and continuance intention [40]. The positive impacts of confirmation on effort expectancy were confirmed by [41]. The positive confirmation of users' perceptions about effort expectancy will influence satisfaction positively. This is the case because the users are aware of the benefits of using the system, and by evaluating their perceptions about the system's benefits after initial use, the users can attune their perceptions according to the reality [40]. Our next hypothesis is as follows:

H4. Effort expectancy has a positive relationship with (a) perceived usefulness, (b) satisfaction, and (c) confirmation.

Social influence refers to an individual's degree of importance given to the beliefs of others that he/she should use new and innovative technology [39]. Several studies have confirmed the positive impacts of social influence on m-banking usage intention $[3,5]$. Ref. [15] confirmed the direct positive effects of social influence on continuance intention. The users generally come to know about m-banking technology through social interaction. They then adopt it, and after getting experience, they adjust their pre-usage perceptions. Therefore, the users' expectations on m-banking are confirmed or disconfirmed, which effects the postusage social perceptions and satisfaction, and this affects continuance intention [46]. Therefore, in the context of mobile banking continuous use, we expect mediated impacts of social influence on users' satisfaction and continuance intentions. Hence, we hypothesize:

H5. Social influence is positively related to (a) satisfaction and (b) continuance intention.

The UTAUT model posits that facilitating conditions play a vital role in technology adoption. Ref. [39] defined facilitating conditions as an individual's belief as to what extent a technical and organizational infrastructure can boost the use of the system. The users of m-banking need specific skills, such as operating and configuring mobile phones to use the wireless Internet [49]. If either the users are not skilled or the necessary resources do not exist, m-banking will be difficult for them. The significant impacts of facilitating conditions on behavioural intention (and/or usage behaviour) have been confirmed by many researchers $[6,43,49]$. According to [46], the availability of more resources and assistance enhances satisfaction, which impacts continuance intention.

Moreover, the availability of appropriate resources impacts an individual's attitude in adopting the technology; furthermore, access to adequate resources disconfirms users' pre-usage beliefs [46]. If adequate resources are available to users, they will have fewer reasons for not engaging themselves in the activity [46]. This study projects that the cognitive dissonance is applicable to mobile banking due to its certain 
facilitation, namely, effort expectancy, facilitating conditions, etc. By using adequate resources, the $\mathrm{m}$-banking users, in their pre-adoption stage, will confirm their expectations from the service. Moreover, it will help them in adjusting their perceptions. Hence, we posit that:

H6. Facilitating conditions are positively related to (a) satisfaction, (b) continuance intention, and (c) confirmation.

3.5. Trust in M-Banking. Initial trust is a person's eagerness to accept risks aimed at fulfilling a need with no previous experience or reliable information [19, 20]. If the users do not have initial trust, they will not be ready to adopt a new service $[54,55]$. Personal, institutional, and environmental forces influence initial trust [56]. Specific characteristics of a firm, such as capability, size, integrity, goodwill, reputation, or trademark, come under the purview of institution-based trust [57].

Lack of confidence in m-banking enhances risk perception, which at later stages affects trust negatively. In e-business contexts, the significance of trust has been confirmed by many researchers [14]. Ref. [54] studied $\mathrm{m}$-banking by using the Initial Trust Model in which initial trust is explained by structural assurance, trust propensity, relative benefits, and firm reputation. Ref. [58] conducted a study in Finland and South Africa to examine the continuous usage behaviour of $\mathrm{m}$-banking. They confirm that trust significantly affects continuance intention. Extant literature projects positive impacts of trust on continuance intention and satisfaction [15]. They posited that the consumers having trust in $\mathrm{m}$-banking were found to be satisfied with the service. Hence, we hypothesize:

H7. Trust is positively related to (a) satisfaction and (b) continuance intention.

Based on the theoretical foundations presented in Section 3, Model-1 is proposed as shown in Figure 1.

After building the above theoretical underpinnings, study 1 employs a qualitative procedure to further explore consumers' $\mathrm{m}$-banking decision-making in the context of an emerging economy, through in-depth interviews. The following section details study 1 , which is a qualitative exploration via interviews.

\section{Study 1: Qualitative Exploration via Interviews}

Study 1 aims to seek consumers' feedback regarding their $\mathrm{m}$-banking experience, such as feedback after the initial use, and to identify factors influencing their m-banking continuance. This study also attempts to complement existing literature themes and to identify novel themes (if any) based on consumers' perceptions and experiences. To capture the feedback of experienced m-banking users, a purposive sampling technique was used. Therefore, only those respondents who had significant experience of using m-banking services in Saudi Arabia were selected for the interviews. To maintain a broader perspective, we interviewed twelve respondents from diverse backgrounds.

The interview transcripts were coded by two independent researchers using the MAXQDA 18 tool for directed qualitative content analysis. To check the reliability of the codes, the two coding schemes were compared before interpreting the results. The coding made by the two coders was $71 \%$ similar, and the coding was stabilised by following the InterCoder agreement [59].

4.1. Major Findings of Study 1. The results of interview coding and frequency analysis supported the importance of all literature-based variables from UTAUT and ECM. Besides, the qualitative analysis identified five new factors, namely, perceived security concerns, perceived ubiquity, perceived risk, perceived autonomy, and mobile technology related to the m-banking continuance. The mobile technology was excluded due to its low frequency (only two instances), while the perceived risk factor was removed, as perceived security concerns covered the concept. Moreover, the respondents did not show highrisk perceptions toward $\mathrm{m}$-banking, as is evident from the following statements:

"I feel no risk due to multi-layered authentication."; "I feel no risk due to secured and updated infrastructure."; "I feel less risk because m-banking is safer than PC banking."; "I do not feel any risk while using my-banking services."

Following the analysis of two independent researchers, twelve themes were extracted, which further led to three additional constructs (i.e., perceived security concerns, perceived ubiquity, and perceived autonomy) and literaturebased constructs (i.e., ECM and UTAUT). Although these concepts already exist in the IS and consumer behaviour literature $[9,10,37]$, our results show that these factors are also relevant to study consumer decision-making toward $\mathrm{m}$-banking. Notably, perceived security concerns (PSC) emerged as an additional variable related to consumers' m-banking decision-making. PSC refers to consumers' concerns about the safety of payments and personal information [60]. The respondents expressed the following examples of various security concerns:

"Losing a mobile phone can result in disclosure of personal banking information such as username and password."

"They (banks) should provide the latest security updates (antivirus) to their clients (m-banking customers)."

"The banks have to focus on enhancing their systems from a security perspective."

"The banks should provide insurance for $\mathrm{m}$-banking services to safeguard and refund in case of hacking or security breach."

"I hope that the security features will get better in the future." 


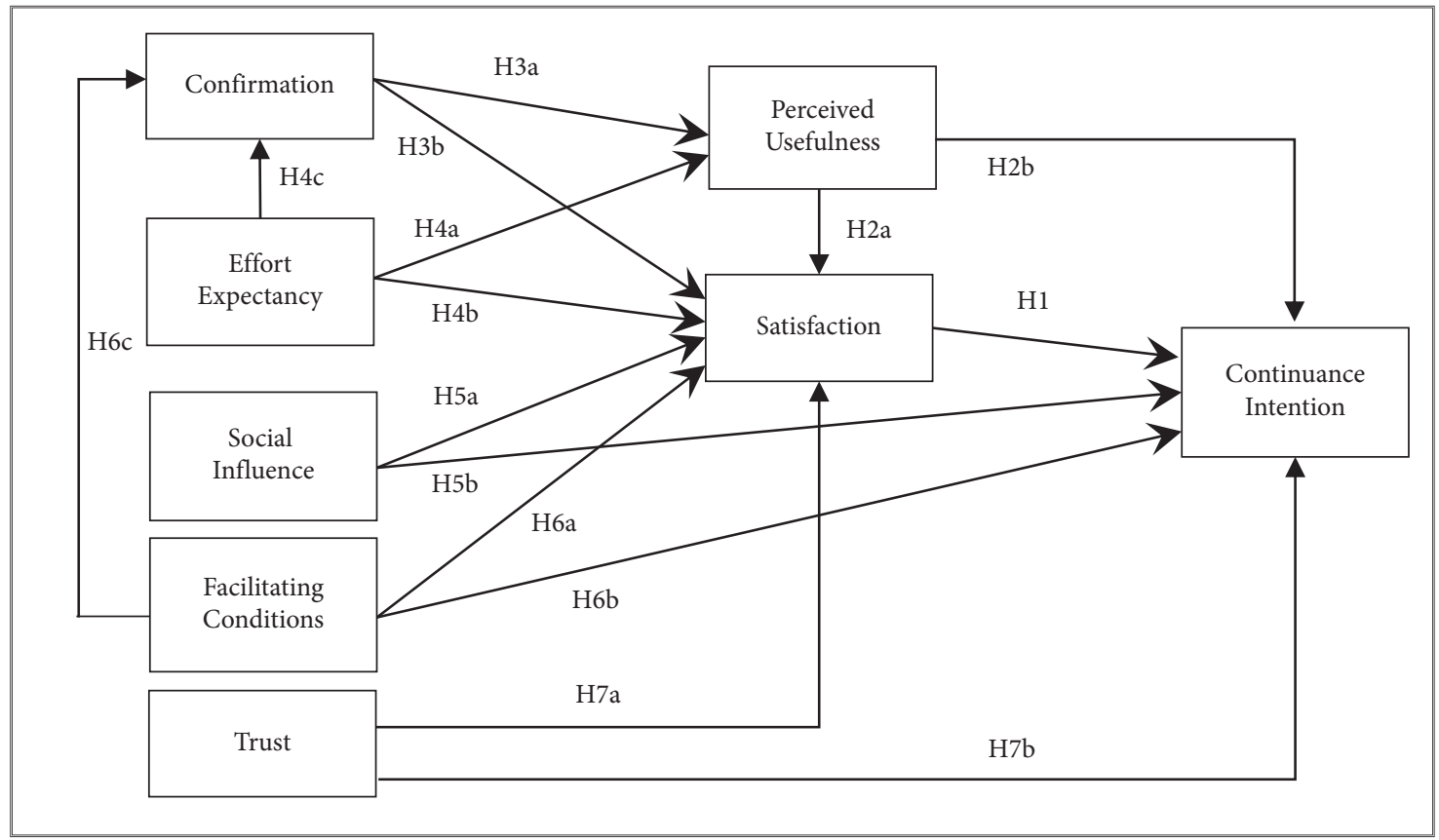

Figure 1: Conceptual model-1based on UTAUT and ECM.

The second additional variable identified from the interviews was perceived ubiquity. According to [61], perceived ubiquity refers to the usage, flexibility, and accessibility of mobile services, independent of time and location. The following are a few examples of responses related to the Perceived Ubiquity of $\mathrm{m}$-banking:

"We can access m-banking from anywhere."

"M-banking gives you freedom with time and location."

"M-banking provides 24/7 access to the bank".

"We can access and pay bills from everywhere and at any time."

"The banks want their presence with customers at all time so that they may not switch to other banks."

The third construct that emerged from the interviews was perceived autonomy. Ref. [62] described perceived autonomy as the desire of users to engage themselves in selfinitiating and self-regulating activities. The respondents expressed their feelings related to the perceived autonomy of $\mathrm{m}$-banking through the following statements:

"I feel that I am independent and in charge of everything when I am in m-banking."

"I can customise various m-banking services as per my requirements."

"I feel freedom for any transaction I want."

"Autonomy is the main reason behind my m-banking usage."

"It's my own choice to select the service."
"M-banking gives me more autonomy and control over my banking services $24 / 7$ ".

The qualitative interviews in study 1 were useful in exploring users' motivations towards m-banking continuance. The following section discusses the theoretical underpinnings for the various constructs proposed in the conceptual model-1 and the additional variables identified through qualitative interviews.

4.2. Perceived Ubiquity. Since 2002, the ubiquity construct has been widely used in marketing research [63, 64]. Following [63], we present our understanding of ubiquity as the ease of mobile banking use in terms of time and place based on the provided flexibility and accessibility of banking services from banks. While studying an individual's mobile payment intentions, [64] argued that the ubiquitous nature of wireless devices provides interactivity anywhere and may lead to enhancing the usefulness of wireless services. By using mobile technologies, some activities become more flexible along the spatial and temporal dimensions. This argument is valid to m-banking, and users find it more flexible and useful due to its ubiquitous nature.

Ref. [65] studied the adoption of mobile wireless technology and has found that perceived ubiquity has positive impacts on behavioural intention. Ref. [66] investigated consumers' behaviours regarding mobile shopping and termed ubiquity as instant connectivity. Their results have confirmed the significant impacts of instant connectivity (ubiquity) on the perceived value of mobile shopping. M-banking users are sensitive about time and space, and they need instant connectivity for banking transactions. Upon successful instant connectivity and completion of 
transactions, their perception about the usefulness of $\mathrm{m}$-banking is enhanced, and they are influenced to continue the use of the service. Keeping the above arguments in view, we posit that:

H8. Perceived ubiquity (PUB) is positively related to (a) confirmation, (b) perceived usefulness, and (c) continuance intention.

4.3. Perceived Autonomy. The perceived autonomy construct has its basis in the Self-Determination Theory (SDT). Autonomy refers to users' desire to engage themselves in self-initiating and self-regulating activities [62]. According to [67], autonomy refers to "the experience of choice in the initiation, maintenance, and regulation of activities and the experience of connectedness between one's actions, personal goals, and values." This research defines perceived autonomy as consumers' perceived independence to utilize m-banking based on their own choice and volition.

Prior research has used perceived autonomy in e-learning and motivational contexts [68]. Literature suggests that perceived autonomy significantly contributes to users' attitudes and continuance intentions for e-services [69]. Moreover, positive relationships of perceived autonomy with satisfaction and perceived usefulness have also been observed. In the m-banking context, it is expected that consumers having high perceived autonomy will feel more satisfaction with the service and will perceive m-banking to be more useful. Therefore, it is probable that in the $\mathrm{m}$-banking usage continuation context, perceived autonomy will significantly contribute to confirmation, perceived usefulness, and satisfaction. Hence, we propose:

H9. Perceived autonomy (PA) is positively related to (a) confirmation, (b) perceived usefulness, and (c) satisfaction.

4.4. Perceived Security Concerns. While using online channels, banking customers are often concerned about the disclosure of their information. They perceive risks about the misuse of personal information and the tracking and hacking of transactions. According to researchers, PSCs refers to the worries of consumers about the safety of payments and personal information-for instance, anxiety about unauthorized retrieval, fraud, financial loss, errors, and unauthorized secondary use and data collection [60].

It is observed that users' perceived trust and security concerns affect the espousal of electronic services [10]. The literature also suggests that consumers with high levels of PSC have less trust in e-commerce and e-payments [70]. While studying the barriers of m-payment services, Ref. [22] confirmed that perceived security strongly influences the usage intention. Ref. [71] investigated Chinese consumers' mobile purchase continuance intention and have found significant effects of security perceptions on satisfaction and trust. The literature also confirms the significant impacts of PSC on trust and insignificant direct effects on behavioural intention/continuation intention [70]. Keeping the above discussion in view, we expect that higher PSC will negatively affect consumers' satisfaction, trust, and continuance intention to use m-banking. Moreover, PSC will disconfirm users' expectations; therefore, we hypothesize:

H10. Perceived security concerns (PSC) are negatively related to (a) trust, (b) satisfaction, (c) continuance intention, and (d) confirmation.

Based on the above discussion and the theoretical underpinning envisioned in conceptual model-1, a combined conceptual model depicting the causal relationships among various constructs to study m-banking continuance has been presented in Figure 2.

Figure 2 depicts the proposed conceptual model- 2 of the study.

\section{Study 2: Empirical Testing of the Proposed Model}

This study uses a mixed-methods approach to explore users' $\mathrm{m}$-banking continuance, as it provides rich and deep insights into a phenomenon where using a single method may not be beneficial [72]. The mixed-methods approach is particularly appropriate when prior research exists but is incomplete or needs further exploration [59]. Since the purpose of this research is to validate and extend the current understanding of m-banking continuance, the mixed-method approach is an appropriate methodological choice for this study. From a methodological perspective, Ref. [14] has emphasised the need for unstructured interviews to analyse the behavioural intentions of consumers towards m-banking. According to [15], quantitative studies do not deliver comprehensive information about continuance intentions, and future studies should complement quantitative studies with qualitative interviews for a thorough understanding of consumer decision-making. Ref. [73] suggested that using a mixedmethods approach can provide more detailed information about consumers' attitudes towards m-banking. While most of the studies on m-banking have relied on surveys or interviews, there is limited consensus on the qualitative versus quantitative approach, or a combination of both-that is, a mixed-methods approach.

For study 2, we employed a survey method approach to empirically validate the proposed conceptual model-2. A PLS-based structural equation modelling approach, through SmartPLS 3.2.7, was used to test the psychometric properties of the scale and estimate the relationships in the conceptual model.

5.1. Instrument Development. All measurement items in this study have been adapted from the prior relevant IS adoption and continuance literature. For content validity, the measurement items were sent to five IS researchers who had expertise in m-banking. Based on their recommendations, necessary changes were made to enhance the clarity and readability of the measurement items. Measurement items to measure effort expectancy, social influence, and facilitating conditions were adapted from $[39,49]$. The three items to measure trust were adapted from [74]. Measurement items 


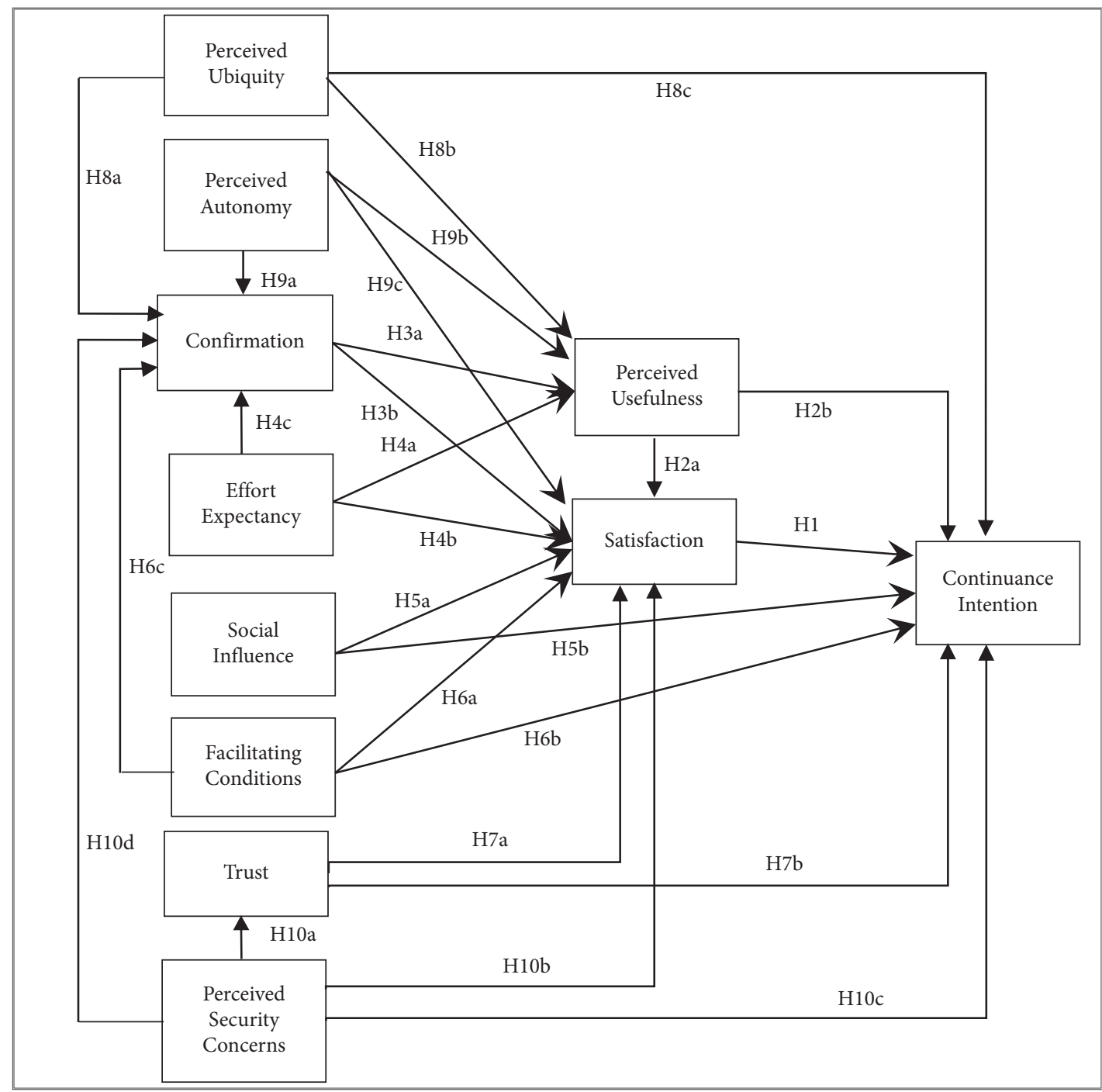

FIgURe 2: Proposed conceptual model-2.

for confirmation, perceived usefulness, satisfaction, and continuance intention were adapted from [40] while items for perceived ubiquity, perceived autonomy, and perceived security concerns were adapted from $[64,69]$, and [71], respectively.

5.2. Sample. In study 2 , an online survey was used to collect data from $\mathrm{m}$-banking users, who were from different regions, banks, age groups, nationalities/other nationals in Saudi Arabia. Based on the judgemental and selective approach, the purposive sampling method was employed to select the respondents. Hence, at the start of the questionnaire, the respondents were asked for the m-banking experience; only respondents with $\mathrm{m}$-banking experience were allowed to continue the survey. The survey resulted in 402 responses, out of which 390 were used for data analysis, as 12 cases were dropped due to low data quality. The majority of the respondents were Saudi nationals having a university degree, and in the age group of 20 to 40 years. Moreover, a significant majority of the sample comprised of males $(72.1 \%)$. The respondents' demographic profile is listed in Table 1.

5.3. Common Method Bias. Any bias occurring in the data due to collection of data for independent and dependent variables using the single source is termed as common method bias (CMB). CMB arises when most of the variance is explained by a single factor [75]. We carried out Harman's single-factor test to assess CMB. This test showed that $36 \%$ (far lower than 50\%) of the variance is explained by a single factor. Thus, CMB is not a concern in our data. Moreover, we also tested VIF values of the latent variables. All VIF values were found to be less than 3. According to [76], VIF values less than 3.3 reveal the absence of CMB.

5.4. Evaluation of Measurement Model. The reliability, validity, and consistency of the scales were assessed as per the recommendations of [77]. For the assessment of reliability, internal consistency (Cronbach's alpha) and composite reliability (CR) along with indicator reliability (outer loading) 
Table 1: Demographic profile of respondents.

\begin{tabular}{lcc}
\hline Demographic information & Frequency & \% age \\
\hline Gender & 281 & \\
Male & 109 & 72.1 \\
Female & & 27.9 \\
\hline Age (years) & 20 & \\
Below 20 years & 170 & 5.1 \\
21 to 30 & 103 & 43.6 \\
31 to 40 & 67 & 26.4 \\
41 to 50 & 30 & 17.2 \\
Above 50 & & 7.7 \\
\hline Education & 22 & \\
High school & 203 & 5.6 \\
Undergraduate & 147 & 52 \\
Graduate & 39 & 37.7 \\
PhD & & 10.3 \\
\hline Experience of using m-banking & 237 & \\
Up to 3 years & 106 & 60.8 \\
4 to 6 years & 32 & 27.2 \\
7 to 9 years & 15 & 8.2 \\
10 years and above & & 3.8 \\
\hline
\end{tabular}

of the scales were assessed. All values of Cronbach's alpha, $\mathrm{CR}$, and outer loadings were significantly above 0.7 , indicating the reliability of the scales (see Table 2).

Subsequently, the necessary validity measures were analysed following the guidelines presented by Refs. [78, 79]. Table 2 shows that the AVE for all constructs is well above 0.5 , suggesting the convergent validity of the scales [78]. To assess the discriminant validity, Fornell-Lacker's criterion and Heterotrait-Monotrait ratio (HTMT) were tested. Table 3 presents the discriminant validity statistics. The diagonal elements are showing the Fornell-Lacker's criterion and the values above the diagonal elements are presenting the HTMT values. The Fornell-Lacker's criterion suggests that AVE values should be higher than the corresponding shared variances [78]. According to [79], the HTMT values among various constructs should be less than 0.90 .

5.5. Model Fit Indices. To examine the ability of the measurement model to describe the observed data, model fit indices, namely, standard root means square residual (SRMR) and normed fit index (NFI) were assessed. The SRMR value is 0.044 . According to [77], an SRMR value lower than 0.10 or 0.12 indicates a well-fit model. The value of NFI was found to be 0.83 which is near to the threshold $(>0.9)$. The SRMR and NFI values reveal the fitness of the observed data according to the hypothesized model.

5.6. EffectSizef $f^{2}$. The effect size $f^{2}$ is the amount of difference in $R^{2}$ value if a specific exogenous variable is omitted to assess whether the omitted construct has a considerable effect on the endogenous variable [77]. The antecedents of CI are FC, PSC, PU, PUb, SAT, and $T$ whose $f^{2}$ values are 0.11 , $0.02,0.02,0.06,0.03$, and 0.06 , respectively. These variables have small effects on the endogenous variable CI $(0.02 \leq f 2 \leq 0.15)$. The exogenous constructs $\mathrm{EE}(0.06)$, FC
(0.02), PA (0.04), PSC (0.04), and PUb (0.02) exert small effects on confirmation. The effects of CONF (0.02), EE (0.11), PA (0.08), and PUb (0.05) on PU are small. Similarly, the effects of CONF (0.06), EE (0.03), FC (0.04), PA (0.04), PSC (0.04), PU (0.05), and $T(0.02)$ on satisfaction are small. The PSC has a medium level effect (0.29) on Trust. Thus, it is concluded that the exogenous variables describe collectively the variances of the endogenous variables $\mathrm{CI}, \mathrm{CONF}, \mathrm{PU}$, and SAT.

5.7. Coefficient of Determination $\left(R^{2}\right)$. The values of $R^{2}$ obtained from PLS Algorithm are CONF (0.380), PU (0.421), SAT (0.594), TR (0.225), and CI (0.609). Three constructs CONF, PU, and TR have comparatively lower $R^{2}$ values while SAT and CI have higher $R^{2}$ values. Thus, it can be concluded that the model provides a moderate degree of predictive accuracy to express the consumers' continuance intention to use mobile banking.

5.8. Structural Model Assessment. Upon using the structural model assessment, the significance of the relationships has been measured in terms of path coefficients $\beta$, critical $t$, and $p$ values, while bootstrapping with 5000 subsamples was used. Table 4 lists the results of the structural model assessment. The results suggest that all hypothesized relationships were supported, except for the effects of $\mathrm{EE} \longrightarrow \mathrm{SAT}, \mathrm{SI} \longrightarrow \mathrm{CI}$, and $\mathrm{SI} \longrightarrow \mathrm{SAT}$.

Effort expectancy $(\beta=0.226, p<0.01)$, facilitating conditions $(\beta=0.147, p<0.01)$, perceived ubiquity $(\beta=0.117$, $p<0.05)$, perceived autonomy $(\beta=0.181, p<0.01)$, and perceived security concerns $(\beta=-0.184, \quad p<0.01)$ have significant effects on confirmation. Hence, hypotheses $\mathrm{H} 4 \mathrm{c}$, H6c, H8a, H9a, and H10d are supported. These five variables-EE, FC, PUB, PA, and PSC-explain 38\% of the variance in confirmation, indicating the importance of the confirmation construct for the continuance intention of m-banking users.

Confirmation $(\beta=0.112, p<0.05)$, effort expectancy $(\beta=0.298, p<0.01)$, perceived ubiquity $(\beta=0.199, p<0.01)$, and perceived autonomy $(\beta=0.248, p<0.01)$ are statistically important in explaining perceived usefulness, supporting H3a, H4a, H8b, and H9b. Four constructs-confirmation, effort expectancy, perceived ubiquity, and perceived autonomy-account for $42.1 \%$ of the variance in perceived usefulness.

Perceived usefulness $(\beta=0.197, p<0.01)$, confirmation $(\beta=0.190, \quad p<0.01), \quad$ facilitating conditions $(\beta=0.156, p<0.01)$, trust $(\beta=0.119, p<0.01)$, perceived autonomy $(\beta=0.162, p<0.01)$, and perceived security concerns $(\beta=-0.155, p<0.01)$ have significant relationships with satisfaction, and these variables explain 59.4\% of variance in satisfaction. However, significant impacts of effort expectancy and social influence on satisfaction were not confirmed. Thus, H2a, H3b, H6a, H7a, H9c, and $\mathrm{H} 10 \mathrm{~b}$ are supported, while $\mathrm{H} 4 \mathrm{~b}$ and $\mathrm{H} 5 \mathrm{a}$ are not upheld. Moreover, the path between perceived security concerns and trust is statistically relevant, and hypothesis H10a is also supported. 
TABLE 2: Reliability statistics summary.

\begin{tabular}{|c|c|c|c|c|c|}
\hline Construct & Items & Indicators' reliability & Composite reliability & $\alpha$ & AVE \\
\hline \multirow{3}{*}{ Continuance intention } & CI1 & 0.874 & 0.923 & 0.874 & 0.799 \\
\hline & $\mathrm{CI} 2$ & 0.902 & & & \\
\hline & $\mathrm{CI} 3$ & 0.905 & & & \\
\hline \multirow{3}{*}{ Confirmation } & CNF1 & 0.864 & 0.879 & 0.794 & 0.709 \\
\hline & CNF2 & 0.884 & & & \\
\hline & CNF3 & 0.774 & & & \\
\hline \multirow{4}{*}{ Effort expectancy } & EE1 & 0.891 & 0.927 & 0.895 & 0.760 \\
\hline & EE2 & 0.892 & & & \\
\hline & EE3 & 0.855 & & & \\
\hline & EE4 & 0.849 & & & \\
\hline \multirow{5}{*}{ Perceived autonomy } & PA1 & 0.839 & 0.919 & 0.890 & 0.694 \\
\hline & PA2 & 0.835 & & & \\
\hline & PA3 & 0.862 & & & \\
\hline & PA4 & 0.831 & & & \\
\hline & PA5 & 0.796 & & & \\
\hline \multirow{3}{*}{ Facilitating conditions } & FC1 & 0.898 & 0.919 & 0.867 & 0.790 \\
\hline & FC2 & 0.871 & & & \\
\hline & FC3 & 0.898 & & & \\
\hline \multirow{4}{*}{ Perceived usefulness } & PU1 & 0.840 & 0.911 & 0.870 & 0.718 \\
\hline & PU2 & 0.871 & & & \\
\hline & PU3 & 0.842 & & & \\
\hline & PU4 & 0.837 & & & \\
\hline \multirow{5}{*}{ Perceived security concerns } & PSC1 & 0.851 & 0.924 & 0.898 & 0.710 \\
\hline & PSC2 & 0.837 & & & \\
\hline & PSC3 & 0.834 & & & \\
\hline & PSC4 & 0.836 & & & \\
\hline & PSC5 & 0.853 & & & \\
\hline \multirow{4}{*}{ Perceived ubiquity } & PUB1 & 0.852 & 0.918 & 0.880 & 0.736 \\
\hline & PUB2 & 0.850 & & & \\
\hline & PUB3 & 0.870 & & & \\
\hline & PUB4 & 0.858 & & & \\
\hline \multirow{2}{*}{ Social influence } & SI1 & 0.890 & 0.915 & 0.818 & 0.843 \\
\hline & SI2 & 0.945 & & & \\
\hline \multirow{4}{*}{ Satisfaction } & SAT1 & 0.855 & 0.919 & 0.883 & 0.740 \\
\hline & SAT2 & 0.875 & & & \\
\hline & SAT3 & 0.854 & & & \\
\hline & SAT4 & 0.858 & & & \\
\hline \multirow{3}{*}{ Trust } & Trust1 & 0.892 & 0.909 & 0.850 & 0.768 \\
\hline & Trust2 & 0.881 & & & \\
\hline & Trust3 & 0.856 & & & \\
\hline
\end{tabular}

Note: CI: Continuance Intention, CNF: Confirmation, EE: Effort Expectancy, PA: Perceived Autonomy, FC: Facilitating Conditions, PU: Perceived Usefulness, PSC: Perceived Security Concerns, PUB: Perceived Ubiquity, SI: Social Influence, SAT: Satisfaction, TR: Trust, AVE: Average Variance Extracted.

Perceived usefulness $(\beta=0.115, p<0.05)$, satisfaction $(\beta=0.163, \quad p<0.01)$, facilitating conditions $(\beta=0.264$, $p<0.01)$, trust $(\beta=0.204, p<0.01)$, perceived ubiquity $(\beta=0.184, p<0.01)$, and perceived security concerns $(\beta=-0.102, p<0.05)$ have significant relationships with continuance intention, and the total variance explained in continuance intention was $60.9 \%$. However, the relationship of social influence with continuance intention was not significant; thus, H1, H2b, H6b, H7b, H8c, and H10c were supported, while H5b was not supported.

Figure 3 presents the results of the structural model.

\section{Discussion and Conclusion}

The study followed a mixed-methods approach to investigate $\mathrm{m}$-banking continuance in the context of an emerging market. Building on the theoretical underpinnings from IS adoption and continuance theories such as EMC and UTAUT, a combination of qualitative (Study 1) and quantitative (Study 2) methods were used to develop a comprehensive theoretical model and to empirically validate the concept. The $R^{2}$ is $60.9 \%$, thus explaining the sufficient predictive power in terms of 
TABle 3: Discriminant validity statistics

\begin{tabular}{lccccccccccc}
\hline & CI & CNF & EE. & FC. & PA. & PSC. & PU. & PUB. & SI. & SAT. & TR \\
\hline CI & $\mathbf{0 . 8 9 4}$ & 0.627 & 0.569 & 0.710 & 0.516 & 0.567 & 0.652 & 0.610 & 0.191 & 0.718 & 0.717 \\
CNF & 0.526 & $\mathbf{0 . 8 4 2}$ & 0.569 & 0.537 & 0.520 & 0.516 & 0.532 & 0.477 & 0.198 & 0.683 & 0.558 \\
EE & 0.504 & 0.478 & $\mathbf{0 . 8 7 2}$ & 0.526 & 0.433 & 0.429 & 0.588 & 0.417 & 0.168 & 0.578 & 0.511 \\
FC & 0.620 & 0.445 & 0.463 & $\mathbf{0 . 8 8 9}$ & 0.459 & 0.453 & 0.564 & 0.424 & 0.138 & 0.629 & 0.594 \\
PA & 0.457 & 0.440 & 0.386 & 0.405 & $\mathbf{0 . 8 3 3}$ & 0.365 & 0.563 & 0.488 & 0.274 & 0.623 & 0.610 \\
PSC & -0.504 & -0.434 & -0.386 & -0.400 & -0.328 & $\mathbf{0 . 8 4 3}$ & 0.465 & 0.416 & 0.172 & 0.582 & 0.540 \\
PU & 0.572 & 0.444 & 0.521 & 0.491 & 0.499 & -0.413 & $\mathbf{0 . 8 4 8}$ & 0.524 & 0.199 & 0.684 & 0.580 \\
PUB & 0.535 & 0.402 & 0.371 & 0.370 & 0.433 & -0.371 & 0.462 & $\mathbf{0 . 8 5 8}$ & 0.134 & 0.505 & 0.515 \\
SI & 0.164 & 0.161 & 0.146 & 0.114 & 0.243 & -0.150 & 0.178 & 0.115 & $\mathbf{0 . 9 1 8}$ & 0.217 & 0.285 \\
SAT & 0.633 & 0.576 & 0.515 & 0.554 & 0.553 & -0.520 & 0.602 & 0.446 & 0.191 & $\mathbf{0 . 8 6 0}$ & 0.666 \\
TR & 0.620 & 0.461 & 0.448 & 0.512 & 0.534 & -0.474 & 0.502 & 0.446 & 0.243 & 0.580 & $\mathbf{0 . 8 7 7}$ \\
\hline
\end{tabular}

Note: CI: Continuance Intention, CNF: Confirmation, EE: Effort Expectancy, PA: Perceived Autonomy, FC: Facilitating Conditions, PSC: Perceived Security Concerns, PU: Perceived Usefulness, PUB: Perceived Ubiquity, SI: Social Influence, SAT: Satisfaction, and TR: Trust.

TABLE 4: Structural model results.

\begin{tabular}{|c|c|c|c|c|c|c|}
\hline Hypothesis & Path & Estimate & Std. deviation & $T$ values & $p$ values & Significance level \\
\hline $\mathrm{H} 1$ & $\mathrm{SAT} \longrightarrow \mathrm{CI}$ & 0.163 & 0.051 & 3.220 & 0.001 & $* * *$ \\
\hline $\mathrm{H} 2 \mathrm{a}$ & $\mathrm{PU} \longrightarrow \mathrm{SAT}$ & 0.197 & 0.046 & 4.311 & $p \leq 0.001$ & $* * *$ \\
\hline $\mathrm{H} 2 \mathrm{~b}$ & $\mathrm{PU} \longrightarrow \mathrm{CI}$ & 0.115 & 0.046 & 2.510 & 0.012 & $* *$ \\
\hline $\mathrm{H} 3 \mathrm{a}$ & $\mathrm{CNF} \longrightarrow \mathrm{PU}$ & 0.112 & 0.053 & 2.102 & 0.036 & $* *$ \\
\hline $\mathrm{H} 3 \mathrm{~b}$ & $\mathrm{CNF} \longrightarrow \mathrm{SAT}$ & 0.190 & 0.046 & 4.165 & $p \leq 0.001$ & $* * *$ \\
\hline $\mathrm{H} 4 \mathrm{a}$ & $\mathrm{EE} \longrightarrow \mathrm{PU}$ & 0.298 & 0.057 & 5.195 & $p \leq 0.001$ & $* * *$ \\
\hline $\mathrm{H} 4 \mathrm{~b}$ & $\mathrm{EE} \longrightarrow \mathrm{SAT}$ & 0.074 & 0.048 & 1.548 & 0.128 & N.S. \\
\hline $\mathrm{H} 4 \mathrm{c}$ & $\mathrm{EE} \longrightarrow \mathrm{CNF}$ & 0.226 & 0.048 & 4.696 & $p \leq 0.001$ & $* * *$ \\
\hline $\mathrm{H} 5 \mathrm{a}$ & $\mathrm{SI} \longrightarrow \mathrm{SAT}$ & 0.006 & 0.036 & 0.153 & 0.879 & N.S. \\
\hline $\mathrm{H} 5 \mathrm{~b}$ & $\mathrm{SI} \longrightarrow \mathrm{CI}$ & -0.003 & 0.032 & 0.107 & 0.915 & N.S. \\
\hline H6a & $\mathrm{FC} \longrightarrow \mathrm{SAT}$ & 0.156 & 0.049 & 3.163 & 0.002 & $* * *$ \\
\hline $\mathrm{H} 6 \mathrm{~b}$ & $\mathrm{FC} \longrightarrow \mathrm{CI}$ & 0.264 & 0.067 & 3.957 & $p \leq 0.001$ & $* * *$ \\
\hline $\mathrm{H} 6 \mathrm{c}$ & $\mathrm{FC} \longrightarrow \mathrm{CNF}$ & 0.147 & 0.050 & 2.949 & 0.003 & $* * *$ \\
\hline $\mathrm{H} 7 \mathrm{a}$ & $\mathrm{TR} \longrightarrow \mathrm{SAT}$ & 0.119 & 0.046 & 2.583 & 0.010 & $* *$ \\
\hline $\mathrm{H} 7 \mathrm{~b}$ & $\mathrm{TR} \longrightarrow \mathrm{CI}$ & 0.204 & 0.054 & 3.796 & $p \leq 0.001$ & $* * *$ \\
\hline $\mathrm{H} 8 \mathrm{a}$ & $\mathrm{PUB} \longrightarrow \mathrm{CNF}$ & 0.117 & 0.049 & 2.391 & 0.017 & $* *$ \\
\hline $\mathrm{H} 8 \mathrm{~b}$ & $\mathrm{PUB} \longrightarrow \mathrm{PU}$ & 0.199 & 0.052 & 3.821 & $p \leq 0.001$ & $* * *$ \\
\hline $\mathrm{H} 8 \mathrm{c}$ & $\mathrm{PUB} \longrightarrow \mathrm{CI}$ & 0.184 & 0.043 & 4.321 & $p \leq 0.001$ & $* * *$ \\
\hline $\mathrm{H} 9 \mathrm{a}$ & $\mathrm{PA} \longrightarrow \mathrm{CNF}$ & 0.181 & 0.055 & 3.288 & 0.001 & $* * *$ \\
\hline $\mathrm{H} 9 \mathrm{~b}$ & $\mathrm{PA} \longrightarrow \mathrm{PU}$ & 0.248 & 0.053 & 4.694 & $p \leq 0.001$ & $* * *$ \\
\hline $\mathrm{H} 9 \mathrm{c}$ & $\mathrm{PA} \longrightarrow \mathrm{SAT}$ & 0.162 & 0.043 & 3.806 & $p \leq 0.001$ & $* * *$ \\
\hline $\mathrm{H} 10 \mathrm{a}$ & $\mathrm{PSC} \longrightarrow \mathrm{TR}$ & -0.474 & 0.049 & 9.680 & $p \leq 0.001$ & $* * *$ \\
\hline $\mathrm{H} 10 \mathrm{~b}$ & $\mathrm{PSC} \longrightarrow \mathrm{SAT}$ & -0.155 & 0.039 & 3.930 & $p \leq 0.001$ & $* * *$ \\
\hline $\mathrm{H} 10 \mathrm{c}$ & $\mathrm{PSC} \longrightarrow \mathrm{CI}$ & -0.102 & 0.043 & 2.384 & 0.017 & $* *$ \\
\hline H10d & $\mathrm{PSC} \longrightarrow \mathrm{CNF}$ & -0.184 & 0.050 & 3.694 & $p \leq 0.001$ & $* * *$ \\
\hline
\end{tabular}

Note: CI: Continuance Intention, CNF: Confirmation, EE: Effort Expectancy, PA: Perceived Autonomy, FC: Facilitating Conditions, PSC: Perceived Security Concerns, PU: Perceived Usefulness, PUB: Perceived Ubiquity, SI: Social Influence, SAT: Satisfaction, and TR: Trust. ${ }^{* * *} p<0.01 ;{ }^{* *} p<0.05 ;{ }^{*} p<0.1$; N.S. $\Rightarrow$ Not Significant.

m-banking consumers. The statistical analysis significantly supported most of the pathways posited in the conceptual model.

Satisfaction has significant effects on continuance intention ( $\mathrm{H} 1)$ that indicates its importance in explaining users' attitudes towards m-banking in their postadoption phase. Significant impacts of perceived usefulness on satisfaction ( $\mathrm{H} 2 \mathrm{a})$ and continuance intention (H2b) were confirmed. This indicates that the high levels of perceived usefulness of m-banking enhance users' satisfaction, which further positively affects their continuous usage intention. These findings of this research thus complement the extant literature $[15,40,46,80]$.
Hypotheses H3a, H3b, H4c, H6c, H8a, H9a, and H10d were also supported, indicating that users' positive confirmation of their anticipation about perceived ubiquity, perceived autonomy, facilitating conditions, and effort expectancy make their perceptions stronger about usefulness of the system. Moreover, this enhances their satisfaction level at the postadoption stage. Furthermore, the confirmation of their security concerns will negatively affect not only perceived usefulness but also satisfaction. These findings are broadly consistent with the existing literature on m-banking $[5,6,9,44]$.

The results support hypothesis $\mathrm{H} 4 \mathrm{a}$ and confirm the significant relationship between EE and PU. After initial 


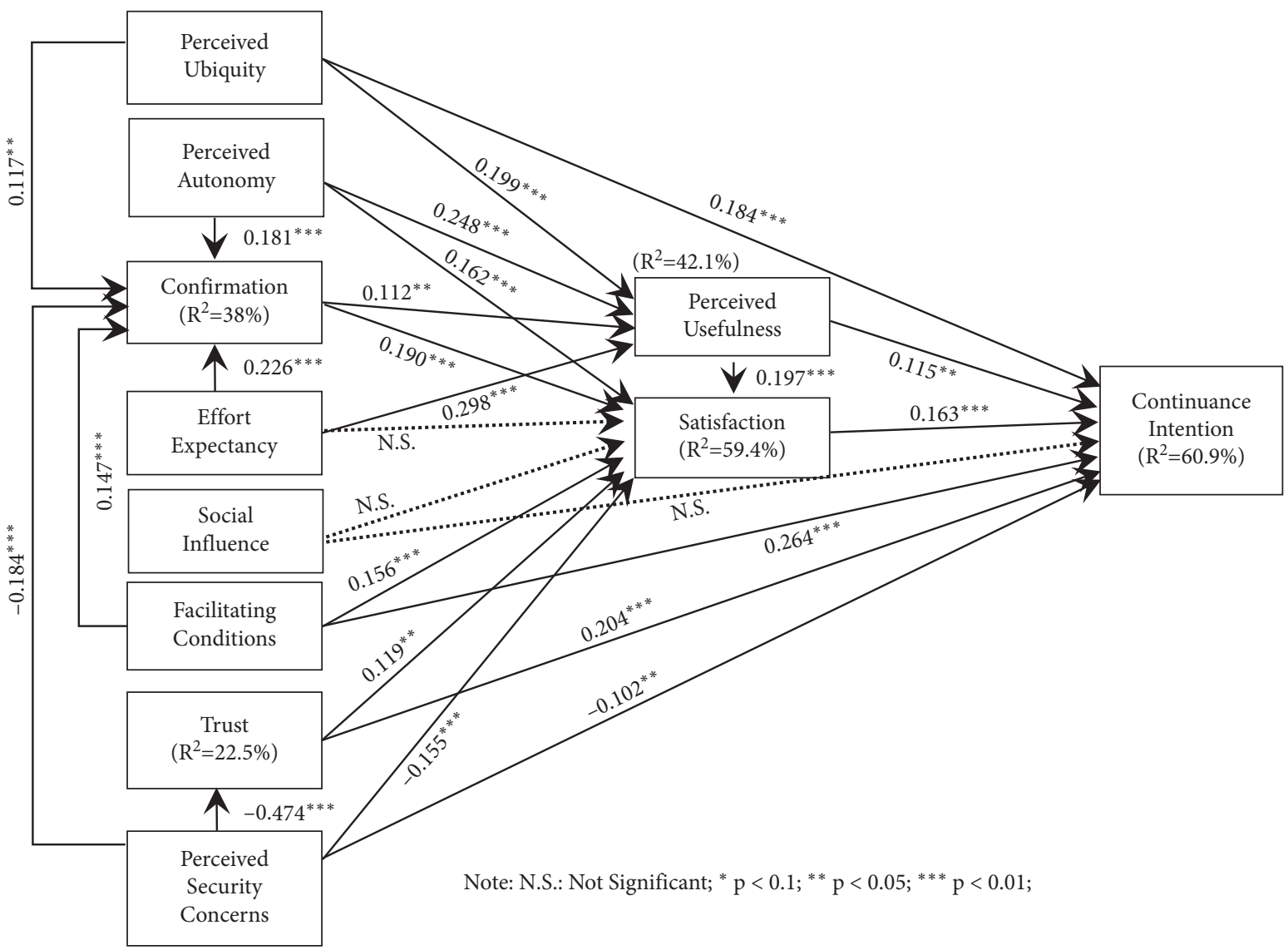

Figure 3: Hypothesis testing (path coefficients). N.S.: not significant; ${ }^{*} p<0.1 ;{ }^{* *} p<0.05 ;{ }^{* * *} p<0.01$.

adoption, their expectations about EE are confirmed (H4c) and show that individuals believe, in the postadoption stage, that they can easily use m-banking and less effort is required to transact with m-banking. Their perceptions of $\mathrm{m}$-banking's usefulness become stronger, and they intend to continue using $\mathrm{m}$-banking. This result is supported by prior research $[2,12,15,46]$.

Three of our hypotheses (H4b, H5a, and H5b) were not supported. The relationship between $\mathrm{EE}$ and satisfaction was found to be nonsignificant ( $\mathrm{H} 4 \mathrm{~b})$. A possible explanation for this is that the users' beliefs about ease of use do not affect their satisfaction level-rather, it only affects their perceptions about usefulness. In the pre-adoption stage, the users need such a service for which less effort is needed while in the postadoption stage, the users' satisfaction level is not dependent on effort expectancy. They perceive effort expectancy to be more important for usefulness of the service but their satisfaction is dependent on factors other than effort expectancy. This result is contrary to the extant research [48]. The data analysis indicates no significant impact of social influence on satisfaction or continuance intention ( $\mathrm{H} 5 \mathrm{a}$ and $\mathrm{H} 5 \mathrm{~b}$ ). Therefore, it is concluded that social influence does not affect users' continuance intention of $\mathrm{m}$-banking. To protect the secrecy and privacy of their bank accounts and transactions, users do not prefer to share information about their transactions. These findings provide support for later research $[6,81]$.
Turning to hypotheses $\mathrm{H} 6 \mathrm{a}$ and $\mathrm{H} 6 \mathrm{~b}$, the positive relationships of facilitating conditions (FC) with users' satisfaction and continuance intention were confirmed. This indicates the importance of FC in describing users' satisfaction and their continuance intentions. The users' perceptions of having required understanding and skills about $\mathrm{m}$-banking make them more satisfied and their continuance intention is influenced positively. Once they have used the service, they have more confidence in the necessary skills and resources that motivate them to continue the service. These outcomes are consistent with extant research $[2,46]$.

$\mathrm{H} 7 \mathrm{a}$ and $\mathrm{H} 7 \mathrm{~b}$ were also found to be significant, thus confirming the intentioned hypothesis. These outcomes indicate the vital role of trust in determining m-banking users' continuance intentions. If the users trust their bank and the entire relevant infrastructure, they will feel more satisfied with the service and intend to continue. These results comply with previous research in different contexts of IS [37, 46, 71, 82].

Hypotheses $\mathrm{H} 8 \mathrm{~b}$ and $\mathrm{H} 8 \mathrm{c}$, hypothesizing positive relationships of perceived ubiquity with $\mathrm{PU}$ and continuance intention, were also supported. This shows that if the m-banking consumers recognize the availability of m-banking without time and location constraints, their perceptions about the usefulness of the service and the intention to continue using the service are positively influenced. These results are in line with existing research 
about mobile wireless technology conducted by [65] but are not consistent with the findings of [64], who did not find a significant effect of perceived ubiquity on the intention to use mobile payments.

We found significant impacts of perceived autonomy on perceived usefulness (H9b) and satisfaction (H9c). These results show that the users' perceptions of autonomy about $\mathrm{m}$-banking positively influence their perceptions about usefulness, and they will feel more satisfied with the service. Furthermore, higher levels of satisfaction and perceptions about usefulness will positively affect users' intentions to continue using the service.

Perceived security concerns have negative impacts on trust (H10a) and satisfaction (H1Ob). These results indicate that more security concerns negatively affect trust and, in turn, affect their continuance intentions. These findings support the results of prior research [57]. Higher perceptions about security concerns also affect users' satisfaction, which has negative impacts on continuance intention. This outcome is in line with extant research [71]. The direct impact of PSC on continuance intention (H10c) was also confirmed. This result is contrary to prior research conducted about e-banking, in which the direct impacts of security on behavioural intention/continuance intentions were not confirmed, while indirect impacts were confirmed. The importance of perceived security concerns for m-banking consumers' continuance intentions is evident from these results.

According to the results above, perceived usefulness contributes significantly in ascertaining consumers' continuance intention. Bankers need to take concrete steps that would positively influence the users' perceptions about the usefulness of $\mathrm{m}$-banking. Providing more tools and facilities to m-banking consumers can boost the consumers' perception of usefulness, and they will feel more autonomy. Such additional features could include value-added services, the ability to add/delete international beneficiaries, and the processing of cheques, for example.

The satisfaction of consumers with service is another essential factor for continuance intention. Prompt responses by bank customers' support departments to customers' queries will enhance customers' perceptions about the ease of use and usefulness, which enhance their satisfaction as a consequence. Customers can easily switch to other banks if they are not satisfied with the bank's service. Moreover, trust and security concerns are also important factors that influence customers' continuance intentions. Hence, in providing security, the banks should make agreements with well-reputed companies to earn users' trust. They should also ensure advanced security levels so that users feel secure while making transactions either in the bank or online.

6.1. Implications to Theory and Practice. This research contributes to the literature on $\mathrm{m}$-banking by offering useful theoretical, methodological, and contextual implications. This study aims at providing an understanding about $\mathrm{m}$-banking usage continuance. For this purpose, the study used a mixed-methods approach. This research incorporated two well-established models, namely, UTAUT and ECM, with intentioned variables in predicting the IS adoption and continuance. By developing an integrated model, the study provides greater understandings about $\mathrm{m}$-banking continuance intentions. Such integration is a significant contribution and a way to expand the field.

From the theoretical perspective, our results endorse and extend the current understanding of $\mathrm{m}$-banking continuance. To study m-banking, our results support the extension of theoretical models such as UTAUT and ECM, by integrating other behavioural and technological constructs, such as perceived autonomy, perceived ubiquity, and perceived security concerns. This study used a mixed-methods approach for developing and testing a model that portrays the acceptance and long-term use of $\mathrm{m}$-banking. The results provided explications for a better understanding of the postadoption behaviours of mobile banking users. Therefore, from a methodological perspective, we recommend mixed methods as the right choice, as it allows researchers not only to develop an in-depth understanding of the subject but also to validate the theoretical relationship empirically. Moreover, given different social, economic, and technological conditions, consumers' responses to online services may not be the same. Therefore, we must consider the contextual situation of the underlying study.

The findings of this research confirm that social influences do not impact users' satisfaction and continuance intentions for $\mathrm{m}$-banking. This indicates that social influence will have no relevance from an $\mathrm{m}$-banking perspective. Our results suggest that perceived ubiquity and perceived autonomy make a significant contribution in predicting the continuance intention. Such a contribution is unique within the framework of m-banking. It is also evident from our results that perceived usefulness is influenced by perceived ubiquity and that it influences continuance intention. The ubiquitous availability of the service would positively affect the perceptions of consumers about the usefulness and their intention to continue usage. Another important finding is related to the users' perceived autonomy of m-banking services. Perceived autonomy was revealed to impact users' confirmation of expectations, satisfaction, and usefulness. Therefore, banks need to provide applications equipped with more autonomous features so that consumers can initiate, maintain, and use m-banking services according to their personal preferences.

Effort expectancy positively impacts perceived usefulness and suggests that banks should focus on preparing their applications to be easier to use and more user-friendly. After initial use, the users' perceptions of usefulness are enhanced if it is easy to use, and consequently, they will intend to continue using the service. Moreover, satisfaction is influenced significantly by facilitating conditions, and they have considerable impact on continuance intention. Therefore, the availability of essential resources and professional support is important in the banking sector to keep customer usage intentions active. In addition, trust and perceived security concerns have significant impacts on users' satisfaction and continuance intentions. Therefore, appropriate security should be provided by the banks to reduce security 
concerns and enhance consumers' trust in the banks and the associated infrastructure. Finally, based on the above recommendations, banks can reformulate their strategies to attract and retain more customers for m-banking services.

6.2. Limitations and Future Research. There exist certain limitations in this research effort, which paves the way for future research prospects. First, for study 1, twelve in-depth interviews were carried out. This sample is relatively small, although this is comparable to past research in the field. Therefore, future research may consider comparatively larger samples. Second, subjects for study 1 and study 2 were recruited from Saudi Arabia. For the generalization of the results, future research may consider testing this model in other geographical contexts with different economic and technological conditions. Third, user demographics, such as education and experience, could play a role in consumers' decision-making towards m-banking. Future studies may consider such factors as moderating variables to produce more in-depth insights. Fourth, our sample for study 2 was heavily dominated by male respondents (72.1\%). However, gender representation is comparable to m-banking users in the context of our study. Fifth, for quantitative analysis, this research used a cross-sectional survey. As m-banking is an emerging field, consumers' attitudes towards such services may change with changes in technological conditions. Therefore, longitudinal studies may provide a broad understanding of the $\mathrm{m}$-banking usage continuance.

\section{Data Availability}

The quantitative data used to support the findings of this study are available from the corresponding author ihidayaturrehman@ksu.edu.sa upon request.

\section{Conflicts of Interest}

The authors declare that there are no conflicts of interest regarding the publication of this paper.

\section{Acknowledgments}

The authors are thankful to the Deanship of Scientific Research at King Saud University represented by the Research Centre in the College of Business Administration for financially supporting this research. The authors acknowledge and appreciate the support and guidance provided by their friend and colleague Dr. Muhammad Shakaib Akram throughout the preparation of this paper.

\section{Supplementary Materials}

Measurement items of the study have been provided as supplementary material. (Supplementary Materials)

\section{References}

[1] A. A. Alalwan, Y. K. Dwivedi, N. P. P. Rana, and M. D. Williams, "Consumer adoption of mobile banking in Jordan: Examining the role of usefulness, ease of use, perceived risk and self-efficacyConsumer adoption of mobile banking in Jordan," Journal of Enterprise Information Management, vol. 29, no. 1, pp. 118-139, 2016.

[2] P. Thusi and D. K. Maduku, "“'South African millennials' acceptance and use of retail mobile banking apps: An integrated perspectiveSouth African millennials' acceptance and use of retail mobile banking apps: aAn integrated perspective," Computers in Human Behavior, vol. 111, Article ID 106405, 2020.

[3] R. F. Malaquias and Y. Hwang, "Mobile banking use: aA comparative study with Brazilian and U.S. participants," International Journal of Information Management, vol. 44, pp. 132-140, 2019.

[4] K. A. Saeed, "Mobile sServices as a mMeans to cControl: aAn eEmpirical aAssessment," Journal of Computer Information Systems, vol. 0060, no. 004, pp. 1336-11346, 2018.

[5] A. M. Baabdullah, A. A. Alalwan, N. P. Rana, H. Kizgin, and P. Patil, "Consumer use of mobile banking (M-banking) in Saudi Arabia: tTowards an integrated model," International Journal of Information Management, vol. 44, pp. 38-52, 2019.

[6] S. Afshan and A. Sharif, "Acceptance of mobile banking framework in Pakistan," Telematics and Informatics, vol. 33, no. 2, pp. 370-387, 2016.

[7] F. Malaquias, R. Malaquias, and Y. Hwang, "Understanding the determinants of mobile banking adoption: a longitudinal study in Brazil," Electronic Commerce Research and Applications, vol. 30, pp. 1-7, 2018.

[8] C. Changchit, T. Klaus, R. Lonkani, and J. Sampet, "A cCultural cComparative sStudy of mMobile bBanking aAdoption fFactors," Journal of Computer Information Systems, vol. 0060, no. 005, pp. 1484-11494, 2019.

[9] C. Poromatikul, P. De Maeyer, K. Leelapanyalert, and S. Zaby, "Drivers of continuance intention with mobile banking apps," International Journal of Bank Marketing, vol. 38, no. 1, pp. 242-262, 2019.

[10] W. A. Alkhowaiter, "Digital payment and banking adoption research in Gulf countries: aA systematic literature review," International Journal of Information Management, vol. 53, Article ID 102102, 2020.

[11] B. Foroughi, M. Iranmanesh, and S. S. Hyun, "Understanding the determinants of mobile banking continuance usage intention," Journal of Enterprise Information Management, vol. 32, no. 6, pp. 1015-1033, 2019.

[12] S. Yuan, Y. Liu, R. Yao, and J. Liu, "An investigation of users' continuance intention towards mobile banking in China," Information Development, vol. 32, no. 1, pp. 20-34, 2014.

[13] S. C. Chen, "To use or not to use: understanding the factors affecting continuance intention of mobile banking," International Journal of Mobile Communications, vol. 10, no. 5, p. 490, 2012.

[14] A. A. Shaikh and H. Karjaluoto, "Mobile banking adoption: aA literature review," Telematics and Informatics, vol. 32, no. May1, pp. 129-142, 2015.

[15] Y. Sun, L. Liu, X. Peng, Y. Dong, and S. J. Barnes, “"Understanding Chinese users' continuance intention toward online social networks: An integrative theoretical modelUnderstanding Chinese users' continuance intention toward online social networks: an integrative theoretical model," Electronic Markets, vol. 24, no. 1, pp. 57-66, 2014.

[16] H. Kang, M. J. Lee, and J. K. Lee, "Are yYou sStill with uUs? A sStudy of the pPost-aAdoption dDeterminants of sSustained uUse of mMobile-bBanking sServices," Journal of Organizational Computing \&and Electronic Commerce, vol. 22, no. 2, pp. 132-159, 2012. 
[17] J. C. Ho, C.-G.C. G. Wu, C.-S.C. S. Lee, and T.-T. T.T. T. T. Pham, "Factors affecting the behavioral intention to adopt mobile banking: aAn international comparison," Technology in Society, vol. 63, Article ID 101360, 2020.

[18] A. Shankar, C. Jebarajakirthy, and M. Ashaduzzaman, "How do electronic word of mouth practices contribute to mobile banking adoption?" Journal of Retailing and Consumer Services, vol. 52, Article ID 101920, 2020.

[19] W. Chaouali and N. Souiden, "The role of cognitive age in explaining mobile banking resistance among elderly people," Journal of Retailing and Consumer Services, vol. 50, pp. 342-350, 2019.

[20] M. A. Shareef, A. Baabdullah, S. Dutta, V. Kumar, and Y. K. Dwivedi, "Consumer adoption of mobile banking services: aAn empirical examination of factors according to adoption stages," Journal of Retailing and Consumer Services, vol. 43, pp. 54-67, 2018.

[21] H. E. Hassan and V. R. Wood, “"Does country culture influence consumers' perceptions toward mobile banking? A comparison between Egypt and the United StatesDoes country culture influence consumers' perceptions toward mobile banking? A comparison between Egypt and the United States," Telematics and Informatics, vol. 46, Article ID 101312, 2020.

[22] V. L. Johnson, A. Kiser, R. Washington, and R. Torres, "Limitations to the rapid adoption of M-payment services: uUnderstanding the impact of privacy risk on M-Payment services," Computers in Human Behavior, vol. 79, pp. 111-122, 2018.

[23] D. Mehrad and S. Mohammadi, "Word of mouth impact on the adoption of mobile banking in Iran," Telematics and Informatics, vol. 34, no. 7, pp. 1351-1363, 2017.

[24] H. Mohammadi, "A study of mobile banking loyalty in Iran," Computers in Human Behavior, vol. 44, pp. 35-47, 2015.

[25] C. Tam and T. Oliveira, "Understanding the impact of m-banking on individual performance: DeLone \& McLean and TTF perspectiveUnderstanding the impact of $\mathrm{m}$-banking on individual performance: DeLone \& McLean and TTF perspective," Computers in Human Behavior, vol. 61, pp. 233-244, 2016.

[26] R. F. Malaquias and A. F. Silva, "Understanding the use of mobile banking in rural areas of Brazil," Technology in Society, vol. 62, Article ID 101260, 2020.

[27] "Digital 2020: Saudi Arabia-DataReportal-Global Digital Insights," 2020, https://datareportal.com/reports/digital2020-saudi-arabia.

[28] I. M. Al-jabri, ““The intention to use mobile banking : Further evidence from Saudi Arabia The intention to use mobile banking : Further evidence from Saudi ArabiaThe intention to use mobile banking: fFurther evidence from Saudi Arabia," South African Journal of Business Management, vol. 46, no. 1, pp. 23-34, 2015.

[29] "Statista," 2021, https://www.statista.com/outlook/296/110/ digital-payments/saudi-arabia\#market-revenue.

[30] "Statista," 2019, https://www.statista.com/statistics/741129/ saudi-arabia-interest-in-online-banking-services-by-offer/.

[31] S. Al-Otaibi, N. R. Aljohani, M. R. Hoque, and F. S. Alotaibi, "The satisfaction of Saudi customers toward mobile banking in Saudi Arabia and the United Kingdom," Journal of Global Information Management, vol. 26, no. 1, pp. 85-103, 2018.

[32] S. Cheaa, Luo, and M. M. Luob, "Post-aAdoption bBehaviors of E-sService cCustomers: tThe iInterplay of cCognition and
eEmotion," International Journal of Electronic Commerce, vol. 12, no. 3, pp. 29-56, 2008.

[33] S. S. Kim and J.-Y. Son, "Out of dDedication or cConstraint? A dDual mModel of pPost-aAdoption pPhenomena and iIts eEmpirical tTest in the cContext of oOnline sServices," MIS Qquarterly, vol. 33, no. 1, pp. 49-70, 2009.

[34] W. Chaouali, I. Ben Yahia, R. Lunardo, and A. Triki, "Reconsidering the "what is beautiful is good" effect: wWhen and how design aesthetics affect intentions towards mobile banking applications," International Journal of Bank Marketing, vol. 37, no. 7, pp. 1525-1546, 2019.

[35] P. Avornyo, J. Fang, C. O. Antwi, M. O. Aboagye, and E. A. Boadi, "Are customers still with us? The influence of optimum stimulation level and IT-specific traits on mobile banking discontinuous usage intentions," Journal of Retailing and Consumer Services, vol. 47, pp. 348-360, 2019.

[36] J. Sripalawat, M. Thongmak, and A. Ngramyarn, "M-banking in metropolitan bangkok and a comparison with other countries," Journal of Computer Information Systems, vol. 51, no. 3, pp. 67-76, 2011.

[37] S. K. Sharma and M. Sharma, "Examining the role of trust and quality dimensions in the actual usage of mobile banking services: aAn empirical investigation," International Journal of Information Management, vol. 44, pp. 65-75, 2019.

[38] M. S. Akram, A. Malik, M. A. Shareef, M. Awais Shakir Goraya, M. Akhter, and M. A. Shakir, "'Exploring the interrelationships between technological predictors and behavioral mediators in online tax filing : The moderating role of perceived riskExploring the interrelationships between technological predictors and behavioral mediators in online tax filing: tThe moderating role of perceived risk," Government Information Quarterly, vol. 36, no. 2, pp. 1237-15251, Apr2019.

[39] V. Venkatesh, M. G. Morris, G. B. Davis, and F. D. Davis, "User acceptance of information technology: tToward a unified view," MIS Quarterly: Management Information SystemsMIS Quarterly, vol. 27, no. 3, pp. 425-478, 2003.

[40] A. Bhattacherjee, "Understanding iInformation sSystems cContinuance: aAn eExpectation-cConfirmation mModel," MIS Quarterly, vol. 25, no. 3, pp. 351-370, 2001.

[41] S. Hong, J. Y. L. Thong, and K. Y. Tam, "Understanding continued information technology usage behavior: aA comparison of three models in the context of mobile internet," Decision Support Systems, vol. 42, no. 3, pp. 1819-1834, 2006.

[42] A. Susanto, Y. Chang, and Y. Ha, "Determinants of continuance intention to use the smartphone banking services: An extension to the expectation-confirmation modelDeterminants of continuance intention to use the smartphone banking services," Industrial Management and Data SystemsIndustrial Management \& Data Systems, vol. 116, no. 3, pp. 508-525, 2016.

[43] A. A. Alalwan, Y. K.A. M. BaabdullahDwivedi, N. P. Rana, K. Tamilmani, Y. K. Dwivedi, and N. P. Rana, "Factors influencing adoption of mobile banking by Jordanian bank customers: eExtending UTAUT2 with trust," International Journal of Information Management, vol. 37, no. 3, pp. 99-110, 2017.

[44] G. Baptista and T. Oliveira, "Understanding mobile banking: tThe unified theory of acceptance and use of technology combined with cultural moderators," Computers in Human Behavior, vol. 50, pp. 418-430, 2015.

[45] V. Bhatiasevi, "An extended UTAUT model to explain the adoption of mobile banking," Information Development, vol. 32, no. 4, pp. 799-814, 2015. 
[46] V. Venkatesh, J. Y. L. Thong, F. K. Y. Chan, P. J.-H.P. J. H. Hu, and S. A. Brown, "Extending the two-stage information systems continuance model: ilncorporating UTAUT predictors and the role of context," Information Systems Journal, vol. 21, no. 6, pp. 527-555, 2011.

[47] S. Singh, “'An integrated model combining ECM and UTAUT to explain users' post-adoption behaviour towards mobile payment systemsAn integrated model combining ECM and UTAUT to explain users' post-adoption behaviour towards mobile payment systems," Australasian Journal of Information Systems, vol. 24, 2020.

[48] C. Tam, D. Santos, and T. Oliveira, "Exploring the influential factors of continuance intention to use mobile Apps: eExtending the expectation confirmation model," Information Systems Frontiers, vol. 22, no. -151, pp. 1243-257, 2018.

[49] T. Zhou, Y. Lu, and B. Wang, "Integrating TTF and UTAUT to explain mobile banking user adoption," Computers in Human Behavior, vol. 26, no. 4, pp. 760-767, 2010.

[50] A. P. Oghuma, C. F. Libaque-Saenz, S. F. Wong, and Y. Chang, "An expectation-confirmation model of continuance intention to use mobile instant messaging," Telematics and Informatics, vol. 33, no. 1, pp. 34-47, 2016.

[51] A. Bhattacherjee and G. Premkumar, "Understanding changes in belief and attitude toward information technology usage: a theoretical model and longitudinal test," MIS Qquarterly, vol. 28, no. 2, pp. 229-254, 2004.

[52] R. F. Malaquias and Y. Hwang, "An empirical study on trust in mobile banking: aA developing country perspective," Computers in Human Behavior, vol. 54, pp. 453-461, 2016.

[53] D. Suhartanto, D. Dean, T. A. T. Ismail, and R. Sundari, "Mobile banking adoption in Islamic banks: Integrating TAM model and religiosity-intention modelMobile banking adoption in Islamic banks," Journal of Islamic Marketing, vol. 11, no. 6, pp. 1405-1418, 2019.

[54] G. Kim, B. Shin, and H. G. Lee, "Understanding dynamics between initial trust and usage intentions of mobile banking," Information Systems Journal, vol. 19, no. 3, pp. 283-311, 2009.

[55] H. Xin, A. A. Techatassanasoontorn, and F. B. Tan, "Antecedents of consumer trust in mobile payment adoption," Journal of Computer Information Systems, vol. 55, no. 4, pp. 1-10, 2015.

[56] D. H. McKnight, V. Choudhury, and C. Kacmar, "The impact of initial consumer trust on intentions to transact with a web site: a trust building model," The Journal of Strategic Information Systems, vol. 11, no. 3-4, pp. 297-323, 2002.

[57] P. Pavlou, "Integrating trust in electronic commerce with the technology acceptance model: model development and validation," AMCIS 2001 Proceedings, vol. 159, 2001.

[58] A. A. Shaikh, H. Karjaluoto, and N. B. Chinje, "Consumers' perceptions of mobile banking continuous usage in Finland and South Africa," International Journal of Electronic Finance, vol. 8, no. 2-4, pp. 149-168, 2015.

[59] A. M. French, “'Let's meet offline: A mixed-methods approach exploring new trends in social networkingLet's meet offline," Information Technology and PeopleInformation Technology \& People, vol. 30, no. 4, pp. 946-968, 2017.

[60] J. Y. Tsai, S. Egelman, L. Cranor, and A. Acquisti, "The effect of online privacy information on purchasing behavior: aAn experimental study," Information Systems Research, vol. 22, no. 2, pp. 254-268, 2011.

[61] S. Okazaki, H. Li, and M. Hirose, "Consumer pPrivacy cConcerns and pPreference for dDegree of rRegulatory cControl," Journal of Advertising, vol. 38, no. 4, pp. 63-77, 2009.
[62] E. L. Deci and R. M. Ryan, "The sSupport of aAutonomy and the cControl of bBehavior," Journal of Personality and Social Psychology, vol. 53, no. 6, pp. 1024-1037, 1987.

[63] S. Okazaki and F. Mendez, "Perceived uUbiquity in mMobile sServices," Journal of Interactive Marketing, vol. 27, no. 2, pp. 98-111, 2013.

[64] L. Schmidthuber, D. Maresch, and M. Ginner, "Disruptive technologies and abundance in the service sector-toward a refined technology acceptance model," Technological Forecasting and Social Change, vol. 155, Article ID 119328, 2020.

[65] S. Kim and G. Garrison, "Investigating mobile wireless technology adoption: aAn extension of the technology acceptance model," Information Systems Frontiers, vol. 11, no. 3, pp. 323-333, 2009.

[66] E. Ko, E. Y. Kim, and E. K. Lee, "Modeling consumer adoption of mobile shopping for fashion products in Korea," Psychology and Marketing, vol. 26, no. 7, pp. 669-687, 2009.

[67] J. P. Connell, "Context, self, and action: aA motivational analysis of self-system processes across the life span," in The Self in Ttransition: Infancy to CchildhoodUniversity of Chicago Press, Chicago , IL, USA, 1990.

[68] R. Mobarhan and A. Abdul Rahman, "Understanding E-pPortfolio cContinuance iIntention among sStudents: aA sSelf-dDetermination pPerspective," in Proceedings of the PACIS 2015, Singapore, 2015.

[69] W. Bhuasiri, H. Zo, H. Lee, and A. P. Ciganek, "User aAcceptance of e-government sServices: eExamining an e-tax fFiling and pPayment sSystem in Thailand," Information Technology for Development, vol. 22, no. 4, pp. 672-695, 2016.

[70] J.-W. Lian, "Critical factors for cloud based e-invoice service adoption in Taiwan: aAn empirical study," International Journal of Information Management, vol. 35, no. 1, pp. 98-109, 2015.

[71] L. Gao, K. A. Waechter, and X. Bai, ““Understanding consumers' continuance intention towards mobile purchase: A theoretical framework and empirical study - A case of ChinaUnderstanding consumers' continuance intention towards mobile purchase: aA theoretical framework and empirical study-aA case of China," Computers in Human Behavior, vol. 53, pp. 249-262, 2015.

[72] V. Venkatesh, S. Brown, S. A.H. BalaBrown, and H. Bala, "“Bridging the Qualitative-Quantitative Divide: Guidelines for Conducting Mixed Methods Research in Information SystemsBridging the qQualitative-qQuantitative dDivide: gGuidelines for cConducting mMixed mMethods rResearch in iInformation sSystems," MIS Quarterly, vol. 37, no. 1, pp. 21-54, 2013.

[73] A. A. Alalwan, Y. K. Dwivedi, N. P. Rana, and R. Algharabat, “"Examining factors influencing Jordanian customers' intentions and adoption of internet banking: Extending UTAUT2 with riskExamining factors influencing Jordanian customers' intentions and adoption of internet banking: eExtending UTAUT2 with risk," Journal of Retailing and Consumer Services, vol. 40, pp. 125-138, 2018.

[74] N. Koenig-LewisKoenig-Lewis, A. Palmer, and A. Moll, "“Predicting young consumers' take up of mobile banking servicesPredicting young consumers' take up of mobile banking services," International Journal of Bank Marketing, vol. 28 , no. 5, pp. 410-432, 2010.

[75] P. M. Podsakoff, S. B. MacKenzie, J.-Y. Lee, and N. P. Podsakoff, "Common method biases in behavioral research: aA critical review of the literature and recommended remedies," Journal of Applied Psychology, vol. 88, no. 5, p. 879, 2003. 
[76] N. Kock, G. S. Lynn, and G. Lynn, "Lateral collinearity and misleading results in variance-based SEM: aAn illustration and recommendations," Journal of the Association for Information Systems, vol. 13, no. 7, pp. 546-580, 2012.

[77] J. F. Hair Jr., G. T. M. Hult, C. Ringle, and M. Sarstedt, A Pprimer on Ppartial Lleast Ssquares Sstructural Eequation Mmodeling (PLS-SEM), Sage Publications, Los Angeles, CA, USA, 2nd edition, 2017.

[78] C. Fornell and D. F. Larcker, "Evaluating sStructural eEquation mModels with uUnobservable vVariables and mMeasurement eError," Journal of Marketing Research (JMR).Journal of Marketing Research, vol. 18, no. 1, pp. 39-50, 1981.

[79] J. Henseler, C. M. Ringle, and M. Sarstedt, "A new criterion for assessing discriminant validity in variance-based structural equation modeling," Journal of the Academy of Marketing Science, vol. 43, no. 1, pp. 115-135, 2015.

[80] S.-Y. Hung, C.-M. Chang, and S.-R. Kuo, "User acceptance of mobile E-government services: aAn empirical study," Government Information Quarterly, vol. 30, no. 1, pp. 33-44, 2013.

[81] T. Oliveira, M. Faria, M. A. Thomas, and A. Popovič, "Extending the understanding of mobile banking adoption: wWhen UTAUT meets TTF and ITM," International Journal of Information Management, vol. 34, no. 5, pp. 689-703, 2014.

[82] M. Hung, S. Yang, and T. Hsieh, "An eExermination of the dDeterminants of mMobile sShopping cContinuance," International Journal of Electronic Business Management, vol. 10, pp. 29-37, 2012. 